\title{
Influencing Factors of CDM's Performances in Efficiency Improvement of Low-carbon Technology Innovation in China
}

\author{
Kun LUO ${ }^{1, *}$, Rendao YE $^{2}$ \\ ${ }^{1}$ Alibaba Business College, Hangzhou Normal University, Hangzhou, China \\ ${ }^{2}$ College of Economics, Hangzhou Dianzi University, Hangzhou, China \\ *Corresponding author: olivelk@163.com
}

\begin{abstract}
We firstly look into the current status of CDM practices and low-carbon technology innovation efficiency in China. Then several influencing factors of CDM's performances in efficiency improvement are put forward, and further verified in our empirical analysis. Using a logit model, we find that project number, scale and type, CER issuance and success rate, CER price and returns to investments, as well as economic development of host regions, have significant impacts on the probability of efficiency improvement. Impacts of these factors on the rate of efficiency improvement are also estimated.
\end{abstract}

Keywords: Clean Development Mechanism (CDM), low-carbon technology innovation, efficiency improvement, influencing factors, logit model

Cite This Article: Kun LUO, and Rendao YE, "Influencing Factors of CDM's Performances in Efficiency Improvement of Low-carbon Technology Innovation in China." Journal of Business and Management Sciences, vol. 6, no. 2 (2018): 36-42. doi: 10.12691/jbms-6-2-2.

\section{Introduction}

Low-carbon economy is regarded as an ultimate path to the coordination among economic growth, energy consumption and carbon emission reduction, especially for a large developing country like China. Its microeconomic foundation lies mostly in enterprises' innovation and application of low-carbon technology. However, Chinese enterprises' low-carbon technology innovation efficiencies are found to be rather low over years, even in the most developed regions of the country [1]. This inefficiency seems to be understandable, since enterprises generally lack incentives and capabilities in the costly and risky innovation activities, not to mention the much more demanding low-carbon technology innovation. Now that enterprises alone are inadequate, new mechanisms favoring efficiency improvement need to be introduced urgently.

It is found that the Clean Development Mechanism (CDM) may be such a mechanism to stimulate low-carbon technology innovation in developing countries [2,3]. There are also arguments that China, as the largest host country of CDM projects, can earn not only the revenues of selling carbon emission credits, but also the possibilities of low-carbon technology progress [4]. Furthermore, evidences show that Chinese enterprises can benefit from the financial incentives and technical transfer when undertaking CDM practices. In particular, [5] assessed Chinese enterprises' low-carbon technology innovation efficiencies and their improvement under CDM, and found that CDM could help improve efficiencies significantly, raising not only the probability but also the rate of efficiency improvement.

Still, questions remained unanswered, a most important one of which concerns the influencing factors of CDM's performances in improving low-carbon technology innovation efficiency. In resent research, a bunch of factors are found to be of importance in the expansion of low-carbon technology innovation output, including the scale, type, and transaction costs of CDM projects, as well as government behaviors of host countries [6-12]. However, the improvement of innovation efficiency cannot be simply reduced to the expansion of innovation output, since innovation efficiency is generally defined by the ratio of innovation output with regard to input. Therefore, it still needs to be analyzed what factors matter in improving the efficiency of low-carbon technology innovation under CDM.

In this paper, we firstly look into the current status of CDM practices and low-carbon technology innovation efficiency in China. Then we put forward and verify several influencing factors of CDM's performances in efficiency improvement, including project number, scale and type, CER issuance and success rate, CER price and returns to investments, as well as economic development of host regions. Impacts of these factors on the probability of efficiency improvement are then estimated using a logit model. Impacts on the rate of efficiency improvement are also estimated in our empirical analysis. 


\section{CDM Practices and Low-carbon Technology Innovation Efficiency}

\subsection{CDM Practices}

$\mathrm{CDM}$ is a flexible emission reduction mechanism under the Kyoto Protocol, allowing enterprises from developing countries to earn and trade certified emission reduction (CER, each equivalent to one tonne of $\mathrm{CO}_{2}$ ) credits, while providing industrialized countries with more options in how they meet their emission reduction targets. As the largest host country under CDM, up till January 2018, China is currently hosting 3763 registered projects, nearly $50 \%$ of the total registered projects. These Chinese projects would generate a total issuance of 1070 million CERs throughout the contract periods of 5 to 10 years, accounting for $57 \%$ of all issuance under registered projects, almost 3 times the issuance of Indian and Brazilian CERs combined.

As Figure 1 shows, nearly 20\% of the Chinese projects are small in scale, which generate only $2 \%$ of the total issuance of Chinese CERs. Although featured by lower investment and technical requirements appealing to most enterprises, small projects are contributing much less than non-small ones in achieving emission reduction targets.

CDM projects of various types also differ in their emission reduction outcome. Projects of certain types, such as energy efficiency, $\mathrm{CO}_{2}$ capture and other Green House Gas (GHG) reduction, relate much more closely to emission reduction, compared with other projects like afforestation and reforestation. As in Figure 2, GHG reduction projects account for less than $9 \%$ of the Chinese projects, but manage to generate more than $53 \%$ of the total issuance of Chinese CERs. However, projects of energy efficiency which is a predominant determinant in emission reduction fail to contribute as they are supposed to. Only $6 \%$ of the Chinese projects focus on energy efficiency, and generate almost the same proportion of the total CER issuance, which should have been more achieving in emission reduction.

Figure 3 gives the regional distribution of Chinese projects. Nearly $40 \%$ of the Chinese projects are hosted in top 5 provinces combined, with the less developed regions like Sichuan, Yunnan, and Inner Mongolia each hosting over 350 projects. However, those hosting the most projects are not necessarily achieving the most significant emission reduction targets. As shown in Figure 3, projects in more developed provinces like Zhejiang, Jiangsu and Shandong are generating over $40 \%$ of the total CER issuance. Projects in Sichuan rank No.1 in number, but only generate $6.7 \%$ of the total issuance. It is obvious that CDM projects in different host regions vary in the performances of emission reduction.

CDM practices in China, in various project scale, types and host regions, differ in the outcome of emission reduction. In fact, the achievements of emission reduction fundamentally represent the outputs and affect the efficiency of low-carbon technology innovation under CDM practices.
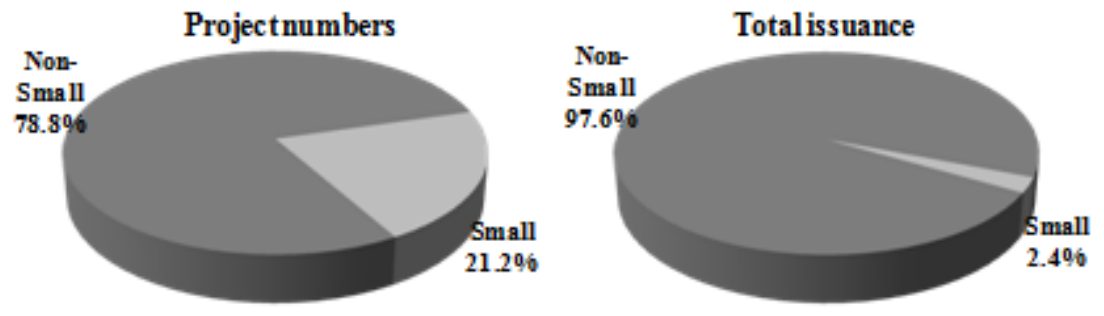

Figure 1. Scale of Chinese projects (Source: UNEP DTU Partnership).
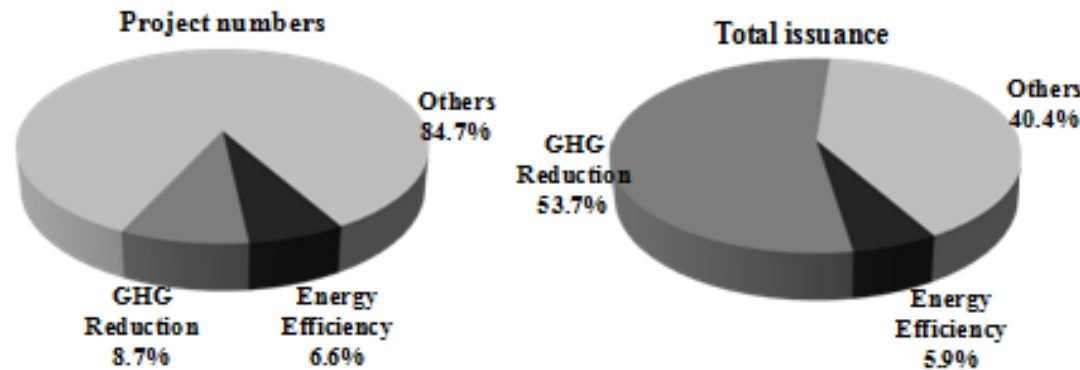

Figure 2. Types of Chinese projects (Source: UNEP DTU Partnership).
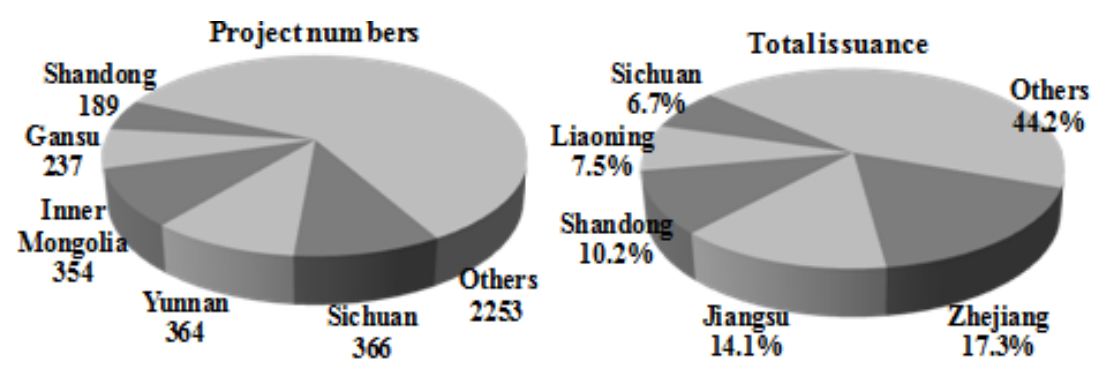

Figure 3. Host regions of Chinese projects (Source: UNEP DTU Partnership) 


\subsection{Low-carbon Technology Innovation Efficiency and Improvement under CDM}

From an input-output perspective, low-carbon technology innovation efficiency is defined by the ratio of outputs with regard to inputs in such activities. Low-carbon technology R\&D expenditures and personnel are often used to indicate capital and human capital inputs respectively. And outputs are usually indicated by reductions in energy consumption and carbon emission, either in the forms of total amount or intensity.

The DEA methodology is often applied to assess the efficiency. In a previous study, we used the DEA model and data of industrial enterprises above designated size in 30 provinces of China, and assessed Chinese enterprises' low-carbon technology innovation efficiencies and their improvement under CDM. It is found that Chinese enterprises are considerably inefficient in low-carbon technology innovation, even in the most developed regions. It is also found that $\mathrm{CDM}$ helps to improve the efficiencies, raising significantly not only the probability but also the rate of efficiency improvement (See [5] for more about CDM's impacts on efficiency improvement).

However, as evidences like Figure 1 to Figure 3 indicate, CDM's performances in efficiency improvement tend to differ. There are needs to further analyze such variation and main influencing factors.

\section{Influencing Factors of CDM's Performances in Efficiency Improvement}

\subsection{Project Number, Scale and Type}

Since low-carbon technology innovation efficiency is found to improve under CDM, numbers of such projects would surely affect the performances in efficiency improvement. Moreover, achievements of emission reduction under CDM, indicating the output of low-carbon technology innovation, vary among different scales and types of projects. Therefore, it makes sense that project number, scale and type matter in determining CDM's performances in improving low-carbon technology innovation efficiency.

\subsection{CER Issuance and Success Rate}

Endeavors to reduce emissions under CDM would only count when CERs are successfully issued. With effects on the accomplishment of emission reduction targets and output of low-carbon technology innovation, the quantity and success rate of CER issuance should be contributing to the performances of CDM on efficiency improvement.

Take projects in Zhejiang and Jiangxi for example. While ranking first and last in total CER issuance, they are found in our previous study to be related to efficiency improvement by $40 \%$ and efficiency deterioration by $33 \%$, respectively.

Take projects in Beijing and Guangxi for another example. These projects, with the mean CER issuance success rates of $99 \%$ and $63 \%$ respectively, perform strikingly differently in efficiency improvement. Our previous assessment showed that low-carbon technology innovation efficiencies improved by 55\% and dropped by $50 \%$ under Beijing and Guangxi projects, respectively.

It seems only sensible to regard CER issuance success rate as an important influencing factor of CDM's performances in efficiency improvement. Unfortunately, however, the Chinese projects are not so successful in terms of CER issuance success rate. Figure 4 gives the CER issuance success rates of top host countries, whose accumulated issued CERs account for 91\% of world's total amount under current registered projects. Although generating the most issued CERs, Chinese projects are undergoing a fairly low issuance success rate of $81 \%$, even slightly lower than the mean rate of all current registered projects. Should the Chinese issuance success rates be raised, more significant effects on efficiency improvement could be expected.

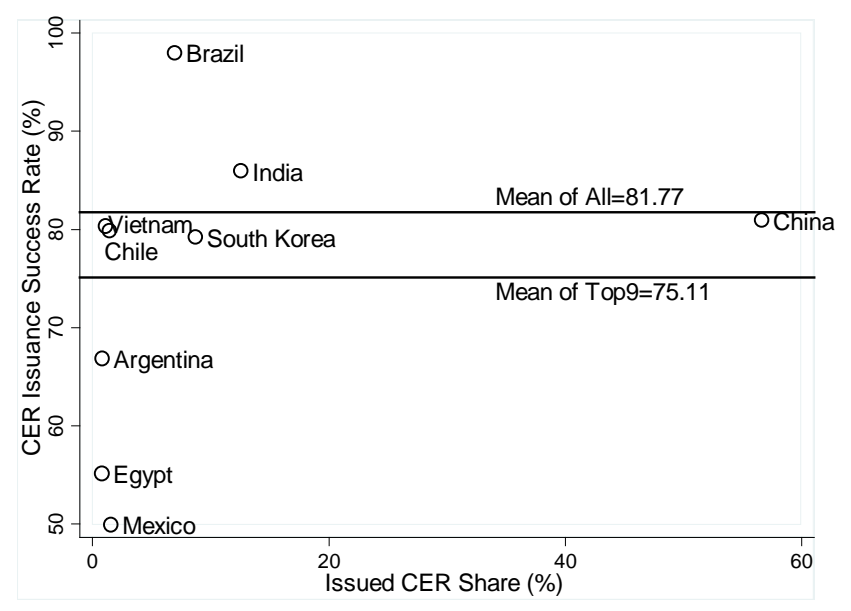

Figure 4. CER issuance success rates of top host countries (Source: UNEP DTU Partnership)

\subsection{CER Price and Returns to Investments}

The amounts of issued CERs as mentioned above affect the outcome of emission reduction, and thus the output and efficiency of low-carbon technology innovation. On the contrary, when issued CERs are traded, their prices determine the revenues and returns to investments of CDM projects. These financial incentives would then stimulate input expansion and efficiency improvement of low-carbon technology innovation under CDM.

Take a wind farm project in Inner Mongolia registered in 2012 for example. CERs issued under this project could be sold at the price of US\$124.4 per tonne of $\mathrm{CO}_{2}$, the maximum of current Chinese projects. Considering the unit investment of US\$577 per tonne of $\mathrm{CO}_{2}$, the price-investment ratio would reach 0.22, 10 times higher than the mean level under current Chinese projects. Such generous returns to investments would definitely encourage low-carbon technology innovation, not only expanding the inputs but also improving the efficiency. As found in our previous study, the efficiency of low-carbon technology innovation improved by $43 \%$ over years in Inner Mongolia. Meanwhile, this province is hosting 354 projects, and generating CERs averagely priced at US\$12.54 per tonne of $\mathrm{CO}_{2}$, nearly 2.3 times the unit investment. Clearly there exist some connections between CER price, returns to investments and efficiency improvement under CDM. 
Although prices and returns to investments of certain projects are considerable, Chinese CERs on the whole can be regarded as under-priced. As shown in Figure 5, the mean price of Chinese CERs is US\$11.58 per tonne of $\mathrm{CO}_{2}, 20 \%$ lower than the mean price of Top 9 host countries. Provided that the Chinese CER prices were raised to the mean level, more desirable performances in efficiency improvement could be expected from CDM practices with higher returns and financial incentives.

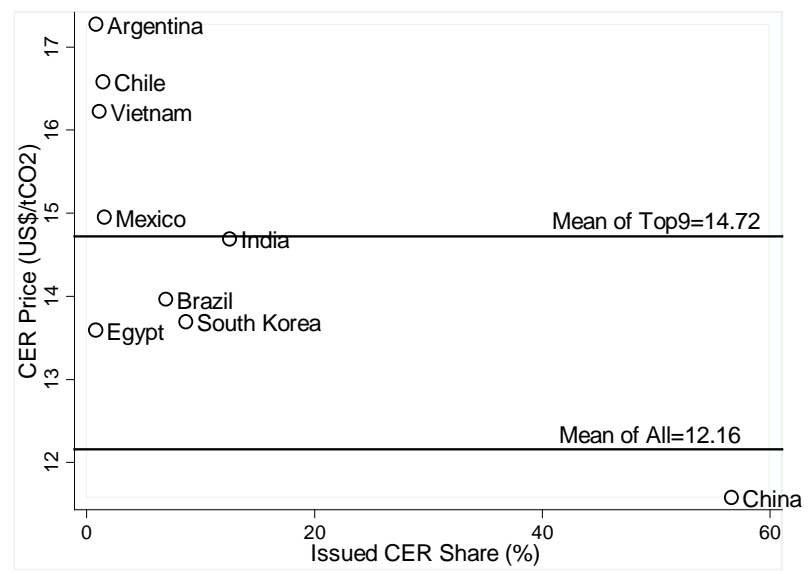

Figure 5. CER prices of top host countries (Source: UNEP DTU Partnership).

\subsection{Economic Development of Host Regions}

Although CER revenues encourage CDM transactions in the first place, some participants may pay too much attention to or even show interest merely in pursuing the financial gains of selling CERs. Under such circumstances, low-carbon technology innovation with high costs and risks would fail to gain sufficient concerns as they deserve, leaving CDM inadequate to contribute to efficiency improvement as anticipated. This is especially the case when projects are hosted in less developed regions, where traders obviously care about financial revenues over advanced technology.

Take technical transfer for example. As shown in Figure 6, CDM projects are more likely to involve technical transfer when hosted in more developed regions. In less developed Gansu and Yunnan, only 3\% to 5\% of all projects claim to ensure technical transfer. Worse still, none of the Guizhou projects involve any sorts of technical transfer. By contrast, projects with technical transfer account for $75 \%$ and $80 \%$ of all projects hosted in most developed Shanghai and Beijing respectively. Furthermore, the Spearman correlation coefficient between shares of projects with technical transfer and GDP per capita of host regions is over 0.5 , significant at the significance level of $1 \%$, indicating positive connections between the occurrence of technical transfer under CDM and economic development of host regions.

Incentives of technical transfer are clearly hampered under CDM projects hosted in less developed regions, let alone the much more demanding low-carbon technology innovation. Considering the impacts of mere financial pursuits on the incentives of low-carbon technology innovation, there is reason to regard the economic development of host regions as an important influencing factor of CDM's performances in efficiency improvement.

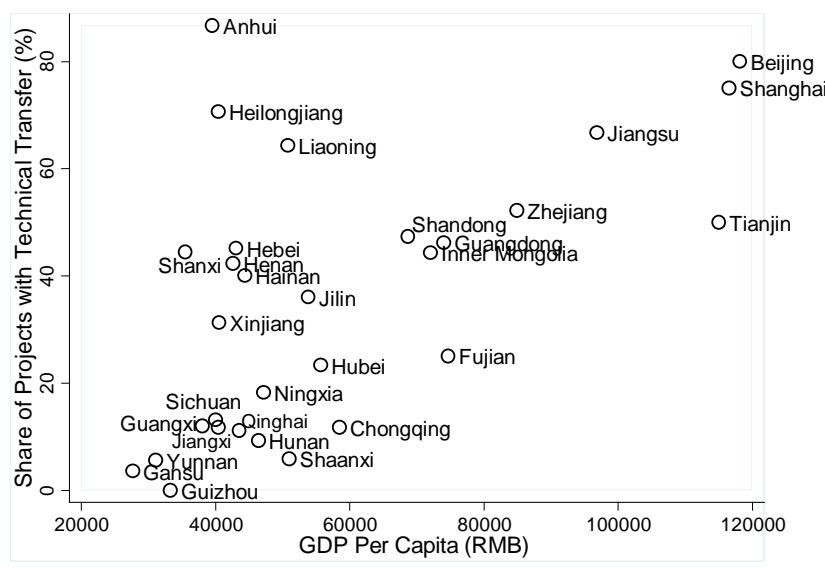

Figure 6. Share of projects with technical transfer by host regions (Source: UNEP DTU Partnership).

\section{Empirical Analysis}

\subsection{Variables}

For further empirical analysis, we use our previous assessment results of low-carbon technology innovation efficiencies and their improvement under CDM in 30 provinces of China based on DEA methodology (See [5]). The efficiency improvement of low-carbon technology innovation is herein defined by the improvement rates in efficiency ranks of enterprises in certain regions over 5 years starting from 2011.

Table 1. Variables of Influencing Factors

\begin{tabular}{|l|l|l|}
\hline Influencing factor & Variable & Specification \\
\hline \multirow{4}{*}{ Project number, scale and type } & $p n$ & Number of registered projects \\
\cline { 2 - 3 } & $p n n s$ & Number of non-small registered projects \\
\cline { 2 - 3 } & $p n e c$ & Number of registered energy efficiency and GHG reduction projects \\
\hline \multirow{2}{*}{ CER issuance and success rate } & $t i$ & Total issuance of CERs \\
\cline { 2 - 3 } & $i s r$ & Issuance success rate \\
\hline \multirow{2}{*}{ CER price and returns to investments } & price & Price of CERs under CDM projects \\
\cline { 2 - 3 } & pir & Ratio of CER price with regard to unit investment \\
\hline \multirow{2}{*}{ economic development of host regions } & GDPpc & GDP per capita of host regions \\
\hline
\end{tabular}


Table 1 gives the influencing factors and variables of CDM's performances in efficiency improvement. We use pn, pnns and pnec to denote the number, scale and type of projects in certain regions, and then verify their influences on CDM's performances in efficiency improvement of enterprises in these regions. Similarly, we analyze the influences of economic development of host regions denoted by GDPpc. As for CER issuance denoted by $t$, we use the regional mean of total CER issuance of CDM projects in certain regions, and verify the influences on the performances in efficiency improvement of enterprises in these regions. Similarly, we study the influences of CER issuance success rate, price and returns to investments denoted by isr, price and pir, respectively.

\subsection{Impacts on Probabilities of Efficiency Improvement}

To analyze the influences of above-mentioned factors on CDM's performances in efficiency improvement, we firstly consider their impacts on the probabilities of efficiency improvement using the logit model as in

$$
P(E I=1 \mid x)=F(x \beta)
$$

where binary EI takes the value of 1 when efficiency improvement occurs and the value of 0 otherwise, $x$ denotes the variables as in Table 1 or their logarithms, and $F(\cdot)$ follows the Logistic distribution.

Table 2 gives the regression results and marginal effects. As project numbers increase by $1 \%$, the probability of efficiency improvement would rise by $4.76 \%$. Slightly higher, the marginal effect of non-small project numbers is $5 \%$, indicating that project scales and numbers do have positive though moderate impacts on the performances in efficiency improvement. By contrast, the influence of project type seems to be much more significant. The probability of efficiency improvement would rise by $18.84 \%$, as numbers of energy efficiency and GHG reduction projects increase by $1 \%$. It makes sense to encourage the undertaking of non-small CDM projects of certain types like energy efficiency and GHG reduction, with a view of fostering more significant improvement in low-carbon technology innovation efficiency.

The marginal effects of CER issuance and success rate are considerably higher. As shown in Table 2, the probability of efficiency improvement would rise by $23.9 \%$ and $26.26 \%$, with a $1 \%$ increase in CER issuance and 1 unit increase in issuance success rate (in percentage), respectively. These results confirm that the quantity and success rate of CER issuance are important determinants and contribute to the output expansion and efficiency improvement of low-carbon technology innovation under CDM. Unfavorably, however, the issuance success rates of Chinese projects are quite low, and therefore more endeavors are needed to ensure successful issuance of CERs. Take projects in Guangxi for example, with the lowest regional mean success rate of $63 \%$. Should the success rate be improved by 1 unit, total CER issuance would rise by $1.55 \%$, meaning the chance of efficiency improvement by a remarkable rate of $37 \%$.

The marginal effects of CER prices and returns to investments are not so considerable as anticipated, but still positive. The probability of efficiency improvement would rise by $8.79 \%$ and $9 \%$, as CER price increase by $1 \%$ and returns to investments (in percentage) increase by 1 unit respectively. These moderate impacts may be attributed to the under-priced CERs and insufficient returns to investments under Chinese projects. Should the prices of Chinese CERs rise to parallel with the other top host countries (See Figure 5), more significant contributions to efficiency improvement could be anticipated from CER prices and returns to investments.

Among the influencing factors listed in Table 1, economic development of host regions is observed to be the most significant one, with the marginal effect of 0.3668 . As GDP per capita of host regions decrease by $1 \%$, the probability of efficiency improvement would drop dramatically by nearly $40 \%$. It is fair to infer that CDM when undertaken in less developed regions could not contribute to efficiency improvement as much as it could in developed regions, since the overwhelming pursuit of financial revenues often blinds enterprises to more rewarding low-carbon technology innovation activities.

Table 2. Impacts of $x$ on the Probability of Efficiency Improvement

\begin{tabular}{|c|c|c|c|c|c|c|c|c|c|}
\hline & \multicolumn{8}{|c|}{ Regression Coefficients } & \multirow{2}{*}{$\begin{array}{c}\text { Marginal Effects } \\
-\end{array}$} \\
\hline constant & - & - & -1.90 & $-10.71^{* *}$ & - & - & - & - & \\
\hline $\ln (p n)$ & $0.27^{*}$ & - & - & - & - & - & - & - & $0.0476^{*}$ \\
\hline $\ln ($ pnns $)$ & - & $0.29^{*}$ & - & & & & & & $0.0505^{*}$ \\
\hline $\ln ($ pnec $)$ & - & & $1.26^{* * *}$ & - & - & - & - & - & $0.1884^{* *}$ \\
\hline $\ln (t i)$ & - & - & - & $2.05^{* *}$ & - & - & - & - & $0.239^{*}$ \\
\hline isr & - & - & - & - & $1.47^{*}$ & - & - & - & $0.2626^{*}$ \\
\hline $\ln ($ price $)$ & - & - & - & - & - & $0.51^{*}$ & - & - & $0.0879^{*}$ \\
\hline pir & - & - & - & - & - & - & $0.55^{*}$ & - & $0.0908^{*}$ \\
\hline $\ln (G D P p c)$ & - & - & - & - & - & - & - & $2.46^{* *}$ & $0.3668^{* *}$ \\
\hline Wald $X^{2}$ & $6.48^{*}$ & $6.55^{*}$ & $2.74^{* * *}$ & $3.87^{* *}$ & $6.22^{*}$ & $6.91^{*}$ & $7.85^{*}$ & $5.23^{* *}$ & - \\
\hline Log likelihood & -14.47 & -14.41 & -12.23 & -12.00 & -15 & -14.4 & -13.76 & -12.75 & - \\
\hline Pseudo $\mathrm{R}^{2}$ & - & - & 0.14 & 0.16 & - & - & - & 0.11 & - \\
\hline
\end{tabular}

Note: ${ }^{*},{ }^{* *},{ }^{* * *}$ Significant at the significance level of $1 \%, 5 \%$ and $10 \%$ respectively. 


\subsection{Impacts on Rates of Efficiency Improvement}

We further analyze the impacts of the above-mentioned influencing factors on the rates of efficiency improvement, using the model as in

$$
R E I=\alpha+\beta x+\varepsilon
$$

where $R E I$ denotes the rate of efficiency improvement, and $x$ denotes the variables as in Table 1 or their logarithms.

Table 3 gives the regression results. As numbers of all projects and non-small ones increase by $1 \%$, efficiency improvement rate would rise by 7.56 units and 7.91 units respectively. Still, influences of project type are more significant. The efficiency improvement rate would rise by 12.74 units with a $1 \%$ increase in numbers of energy efficiency and GHG reduction projects.

The influencing factor of economic development of host regions is also verified. As GDP per capita of host regions increase by $1 \%$, efficiency improvement rate would rise by 3.28 units.

Influences of CER issuance and success rate, as well as CER prices and returns to investments, are also confirmed. The efficiency improvement rate would rise by 5.85 units as CER issuance increases by $1 \%$. By contrast, with an increase in issuance success rate by 1 unit, the efficiency improvement rate would rise dramatically by 42.16 units. And as CER price and returns to investments increase by $1 \%$ and 1 unit respectively, efficiency improvement rate would rise by nearly 14 units. For robustness, we use regional median data other than regional mean data, and get quite similar results.

Table 3. Impacts of $x$ on the Rates of Efficiency Improvement

\begin{tabular}{|l|c|c|c|c|c|}
\hline & Coefficient & $\mathbf{F}$ & $\mathbf{R}^{2}$ & Adjusted $\mathbf{R}^{2}$ & Root MSE \\
\hline $\ln ($ pn $)$ & 7.56 & 21.23 & 0.45 & 0.43 & 39.15 \\
\hline $\ln ($ pnns $)$ & 7.91 & 20.59 & 0.44 & 0.42 & 39.42 \\
\hline $\ln ($ pnec $)$ & 12.74 & 23.69 & 0.48 & 0.46 & 38.17 \\
\hline $\ln (t i)$ & 5.85 & 25.01 & 0.49 & 0.47 & 37.67 \\
\hline $\ln ($ ti)* & 6.90 & 21.24 & 0.45 & 0.43 & 39.15 \\
\hline isr & 42.16 & 20.44 & 0.44 & 0.42 & 39.49 \\
\hline isr* & 41.40 & 21.06 & 0.45 & 0.43 & 39.22 \\
\hline $\ln$ (price) & 14.30 & 22.19 & 0.46 & 0.44 & 38.76 \\
\hline $\ln$ (price)* & 14.40 & 21.68 & 0.45 & 0.43 & 38.97 \\
\hline pir & 14.17 & 23.35 & 0.47 & 0.45 & 38.30 \\
\hline pir* & 11.42 & 18.93 & 0.42 & 0.40 & 40.14 \\
\hline $\ln ($ GDPpc) & 3.28 & 23.90 & 0.48 & 0.46 & 38.09 \\
\hline
\end{tabular}

Note: All significant at the significance level of $1 \%$. *Use regional median for robustness.

\section{Conclusions}

Based on a detailed look into the current status of CDM practices and low-carbon technology innovation efficiency in China, we put forward several influencing factors of CDM's performances in efficiency improvement. They include project number, scale and type, CER issuance and success rate, CER price and returns to investments, as well as economic development of host regions. These factors are then verified in our empirical analysis. Using a logit model, we estimate the impacts of the influencing factors on the probability of efficiency improvement. Impacts on the rate of efficiency improvement are also estimated.

It is found that influences of project type are much more significant than those of project number and scale. To the end of generating more significant efficiency improvement under CDM, it makes sense to encourage the undertaking of non-small, energy efficiency and GHG reduction projects.

It is also found that CER issuance and success rate have considerable impacts on the performances in efficiency improvement, with the latter being a most important determinant. The probability of efficiency improvement would rise by $23.9 \%$ with a $1 \%$ increase in CER issuance. Furthermore, as issuance success rate increase by 1 unit, the probability of efficiency improvement would rise by $26.26 \%$, while the rate of efficiency improvement would rise dramatically by 42.16 units. Therefore, it is essential that more endeavors be devoted to improving the issuance success rate of Chinese projects, which would contribute remarkably to the efficiency improvement of low-carbon technology innovation under CDM.

We also observed positive but moderate impacts from CER prices and returns to investments. As CER price increase by $1 \%$, the probability and rate of efficiency improvement would rise by approximately $9 \%$ and 14 units, respectively. Similar results are observed as for returns to investments. Seeing the overall under-priced CERs and insufficient returns to investments under Chinese projects, it is urgent for the Chinese enterprises undertaking CDM transactions to break through from the current unfavorable situation. And we will work on this in our further research.

Last but not the least, economic development of host regions is verified as an essential influencing factor. As GDP per capita of host regions decrease by $1 \%$, the probability of efficiency improvement would drop dramatically by nearly $40 \%$, while the efficiency improvement rate would decrease by 3.28 units. It is crucial to ensure that CDM practices in less developed regions should be predominated by more efficient lowcarbon technology innovation, rather than driven by mere pursuit of short-term financial revenues.

\section{Acknowledgements}

This research was supported by National Social Science Foundation (Grant No. 12CJY012), and Zhijiang Social Science Scholars Project of Zhejiang Province (Grant No. G115).

\section{References}

[1] Luo, K., Ye, R.D. Measuring Zhejiang Enterprises' Low-carbon Technology Innovation Efficiency: a DEA approach. ICESD2015 (2015 International Conference on Education and Social Development), Nanjing, 2015.

[2] Schneider, M., et al. "Understanding CDM's contribution to technology transfer”, Energy Policy, 2008, 36: 2930-2938. 
[3] Popp, D. "International technology transfer, climate change, and the Clean Development Mechanism", Review of Environmental Economics and Policy, 2011, 5(1): 131-152.

[4] Teng, F., et al. "CDM practice in China: current status and possibilities for future regime”, Energy, 2010, 35(11): 4328-4335.

[5] Luo, K., Ren-Dao Ye, R.D. "The Efficiency Improvement in Lowcarbon Technology Innovation of Chinese Enterprises under CDM: an Empirical Study based on DEA Assessments", Journal of Finance and Economics, 2017, 5(6): 310-315.

[6] Haites, E., et al. "Technology transfer by CDM projects", Climate Policy, 2006, 6: 327-344.

[7] Pan, J.H. Transaction costs for undertaking CDM projects. Institute of World Economics and Politics, 2009.
[8] Seres, S., et al. "Analysis of technology transfer in CDM projects", Energy Policy, 2009, 37: 4919-4926.

[9] Dechezlepretre A, et al. "Technology transfer by CDM projects: a comparison of Brazil, China, India and Mexico", Energy Policy, 2009, 37: 703-711.

[10] Shin, S. "The domestic side of CDM: the case of China", Environmental Politics, 2010, 19(2): 237-254

[11] Wang, B. "Can CDM bring technology transfer to China? An empirical study of technology transfer in China's CDM projects", Energy Policy, 2010, 38: 2572-2585.

[12] Thomas, S., et al. "The drivers and outcomes of the Clean Development Mechanism in China”, Environmental Policy and Governance, 2011, 21(4): 223-239. 